\title{
PENGARUH PERCEIVED USEFULNESS, PERCEIVED EASE OF USE, ATTITUDE TOWARD USING DAN BEHAVIOR INTENTION TO USE TERHADAP ACTUAL SYSTEM USE DALAM IMPLEMENTASI TEKNOLOGI ENTERPRISE RESOURCE PLANNING (ERP) SYSTEM (STUDI PADA END USER ERP SYSTEM DI PT SEMEN GRESIK)
}

\author{
Niswah Muliati
}

muliatiniswah@gmail.com

\begin{abstract}
All dimensions of corporate experience in technology development, therefore the management has to be resourceful and scrupulous to take notice of the latest technological developments as part of efforts to optimize the expected performance and progress. One proof of current information technology advancement is the implementation of Enterprise Resource Planning system (ERP). The results of this research showed an effect of perceived ease of use to perceived usefulness is $72,9 \%(R 2=0,531, t=12,882)$, the perceived ease of use to attitude toward using is $60,1 \%(R 2=0,702, t=8,927)$, the perceived usefulness to attitude toward using is $29,1 \%(R 2=0,702, t=3,564)$, the attitude toward using of behavioral intention to use is $74,1 \%(R 2=0,549, t=14,778)$, and the behavioral intention to use the system to actual system use is $36,2 \%(R 2=0,131, t=4,603)$. This research proves that the user acceptance of a technology strongly influenced by perceived ease of use and perceived usefulness which are emerging acceptances and then behavior intention to use where as to reveal the using of a real system in the intensity of usage time .
\end{abstract}

Keywords : ERP, acceptance.

\section{PENDAHULUAN}

Perilaku pengguna suatu sistem teknologi informasi memiliki peran penting terhadap keberhasilan implementasinya. Menurut Syam (1999), pertimbangan perilaku perlu mendapat perhatian khusus dalam konteks penerapan teknologi informasi. Pendapat ini sejalan dengan Sung (1987) dalam Trisnawati (1998) yang menyatakan bahwa faktor-faktor teknis, prilaku, situasi dan personil pengguna teknologi perlu dipertimbangkan sebelum teknologi diimplementasikan. Henry (1986) dalam Trisnawati (1998) juga mengemukakan bahwa prilaku pengguna, dan personal sistem diperlukan dalam pengembangan sistem, dan hal ini berkaitan dengan pemahaman dan cara pandang pengguna sistem tersebut. Oleh karenanya 
persepsi para personil (orang-orang) yang terlibat dalam implementasi sistem akan berpengaruh pada akhir suatu sistem, kinerja sistem itu berhasil atau tidak, dapat diterima atau tidak, bermanfaat atau tidak jika diterapkan. Hal tersebut merupakan faktor yang mendukung berkembangnya konsep Technology Acceptance Model (TAM) yang diprakarsai oleh Davis (1989) dan banyak dipakai sebagai rujukan penelitian di bidang sistem informasi Davis dalam Wibowo (2008) mengungkapkan bahwa TAM sebagai suatu teorisasi memiliki lima konstruk utama

Penelurusan pada sejumlah karyawan-karyawan PT Semen Gresik yang merupakan end-user aktif sistem JD.Edward, menunjukkan bahwa mereka sebagai end -user menginginkan sistem ERP yang lebih sederhana ( ease of use and user friendly ), lebih terintegrasi, lebih optimal dalam mengakomodir kebutuhan pekerjaan mereka, dan mereka menuntut suatu bentuk sosialisasi sistem baru yang lebih intensif, mengingat pola pelatihan yang dilakukan selama ini yaitu hanya sebagian dari key user yang diikutkan pelatihan langsung sehingga optimalisasi kemampuan seluruh end-user tidak teraktualisasi dengan baik. Besarnya biaya investasi sistem J.D.Edwards senilai 7,3 Miliar Rupiah dan anggaran maintenance yang dikeluarkan secara periodik, merupakan suatu upaya yang dilakukan agar pemanfaatan ERP secara maksimal demi mencapai keuntungan perusahaan dapat terealisasi. Guna mendukung tujuan tersebut, attitude toward using karyawan sebagai end-user terhadap sistem ERP seharusnya menjadi salah satu faktor pendukung yang mendapat perhatian serius sebab akan mempengaruhi actual system use, kualitas pekerjaan dan pengambilan keputusan di masing - masing groupware (unit kerja) yang ada di PT Semen Gresik, yang terdiri atas 4 bagian utama, antara lain: Bagian Keuangan, Litbang, Pemasaran, dan Produksi (Pabrik - Tuban).

\section{TINJAUAN PUSTAKA}

Sistem Informasi dan Teknologi pada Perusahaan Teknologi informasi merupakan satu dari sekian banyak alat bantu yang digunakan para manajer untuk menjembatani perubahan, baik perubahan internal maupun perubahan eksternal. Berkembangnya teknologi informasi berbasis komputer memudahkan organisasi melakukan aktivitas mengakses informasi di mana saja dan kapan saja. Berkaitan dengan aktivitas yang terjadi setiap hari pada perusahaan terutama aktivitas yang ditujukan untuk menghasilkan suatu produk dan jasa, maka disitulah teknologi informasi berperan penting untuk membantu produk menjadi sangat kompetitif (Ellitan dan Anatan, 2007).

Suatu sistem informasi bersifat strategis jika sistem itu mampu mengubah dan mendukung perubahan produk atau jasa, atau cara organisasi bersaing dalam industrinya. Teknologi informasi yang dimiliki oleh suatu organisasi dapat menjadi 
keunggulan strategis karena teknologi tersebut dapat digunakan untuk memenangkan persaingan disebabkan manfaat teknologis, pelayanan yang lebih baik yang dapat diberikan kepada pelanggan, oleh karena itu dapat ditegaskan bahwa teknologi informasi merupakan strategi perusahaan untuk memenangkan persaingan.

Tujuan utama dari SIM adalah membantu pimpinan dalam mengambil keputusan yang tepat. Sehubungan dengan hal itu, tantangan yang lebih besar bagi sistem informasi yang efisien adalah:

(1) kemampuan untuk memberikan macam dan jumlah informasi yang benar-benar dibutuhkan; dan (2) menyampaikan informasi yang memenuhi persyaratan dan mudah dimengerti pimpinan. Informasi

yang baik, yang memenuhi persyaratan adalah: lengkap sesuai kebutuhan, terpercaya dan up to date (aktual) (Syamsi, 2000). Enterprise Resource Planning (ERP) System

Berdasar fungsinya sebagai suatu sistem informasi, ERP merupakan keseluruhan konsep untuk merencanakan dan mengelola sumber daya perusahaan, yaitu berupa paket aplikasi program terintegrasi dan multi modul yang dirancang to serve and support multiple business function (melayani dan mendukung berbagai fungsi dalam perusahaan ), dengan tujuan agar pekerjaan menjadi lebih efisien dan dapat memberikan pelayanan lebih bagi konsumen, dan akhirnya dapat menghasilkan nilai tambah serta memberikan keuntungan maksimal bagi seluruh stake holder (pihak yang berkepentingan) atas perusahaan (Wijaya dan Darudiato, 2009).

Laudon and Laudon (2004) juga mengungkapkan bahwa perangkat lunak ERP mampu memberikan model dan mengotomasi banyak proses bisnis, seperti menyusun daftar pesanan atau pengiriman; dengan tujuan pengintegrasian informasi pada perusahaan dan mengeliminasi jaringan yang kompleks dan memakan biaya antar sistem komputer di tiap area bisnis yang berbeda. Informasi yang sebelumnya terfragmentasi pada sistem tradisional kini dapat mengalir dengan lancar di keseluruhan perusahaan (groupware concept based ) sehingga semua proses bisnis di bagian pabrikasi, akuntansi, sumber daya manusia, dan area lain di perusahaan bisa saling berbagi informasi yang sama. Proses bisnis yang rumit dan terpisah mulai dari penjualan, produksi, keuangan, hingga logistik dapat terintegrasi ke dalam satu proses bisnis yang lebih luas di perusahaan dan mampu melintasi semua level dan fungsi organisasi.

Model Penerimaan Teknologi (Technology Acceptance Model / TAM) TAM dikembangkan oleh Davis pada tahun 1989, berdasarkan model sebelumnya yaitu 
Theory of Reasoned Action (TRA) dengan menambahkan dua konstruk utama yaitu perceived usefulness dan perceived ease of use. Model TAM yang dikembangkan dari teori psikologis, menjelaskan perilaku pengguna suatu teknologi yang berlandaskan pada kepercayaan, sikap, keinginan, dan hubungan perilaku pengguna. Tujuan model ini adalah untuk menjelaskan faktor utama dari perilaku pengguna terhadap penerimaan pengguna teknologi. Secara lebih rinci menjelaskan tentang penerimaan suatu teknologi informasi dengan dimensi-dimensi tertentu yang dapat mempengaruhi diterimanya teknologi tersebut oleh pengguna (Wibowo, 2008).

Jogiyanto (2007) mengungkapkan bahwa konsep TAM yang pertama (belum dimodifikasi) menggunakan lima konstruk utama (yang akan dijelaskan lebih rinci pada sub bab selanjutnya), yaitu:

a. Perceived usefulness / PU (kegunaan persepsian).

b. Perceived ease of use / PEOU (kemudahan penggunaan persepsian).

c. Attitude toward using technology / ATU (sikap menggunakan teknologi).

d. Behavior intention to use / BIU (minat perilaku menggunakan teknologi).

e. Actual technology system use / ASU (penggunaan teknologi sesungguhnya).

Konstruk-konstruk yang merupakan komponen TAM pada penelitian sistem informasi dan teknologi, dimaksudkan untuk penggunaan suatu teknologi tertentu, sehingga penggunaan istilah behavior (perilaku) diartikan sebagai perilaku menggunakan teknologi. Berdasarkan alasan tersebut, TAM juga banyak diungkapkan secara lebih spesifik pada penggunaan teknologi.

\section{MODEL KONSEPSUAL DAN HIPOTESIS}

Merujuk pada sejumlah kajian pustaka yang telah dipaparkan dan gambaran model konsepsual, rumusan hipotesis penelitian ini adalah:

a. Perceived ease of use mempunyai pengaruh terhadap perceived usefulness

b. Perceived ease of use mempunyai pengaruh terhadap attitude toward using

c. Perceived usefulness mempunyai pengaruh terhadap attitude toward using

d. Attitude toward using mempunyai pengaruh terhadap behavior intention to use

e. Behavior intention to use mempunyai pengaruh terhadap actual system use

\section{Model Konsepsual}

\section{METODOLOGI}


Peneltian survey ini dilaksanakan di PT Semen Gresik, yaitu kantor utama di Kota Gresik dan pabrik pengolahan semen di Kota Tuban. PT Semen Gresik merupakan jenis perusahaan manufaktur sehingga divisi yang beroperasi di dalamnya sangat kompleks sesuai dengan keunggulan ERP yaitu mencakup sistem yang luas dan kompleks. Satuan penelitian yang digunakan adalah seluruh groupware fungsional PT Semen Gresik dan populasi penelitian ini adalah keseluruhan karyawan PT Semen Gresik dengan karakteristik yaitu sebagai end-user anggota groupware fungsional (divisi) yang menjadi core business perusahaan sekaligus core business sistem ERP .Data statistik yang diperoleh mengungkapkan bahwa terdapat 1362 orang karyawan yang telah berpengalaman bekerja baik secara manual maupun menggunakan sistem ERP. Struktur organisasi PT Semen Gresik menunjukkan kesetaraan struktural end-user antara semua departemen, oleh karenanya tidak dibedakan tingkatan strata, dan sampel dapat diambil secara acak menggunakan teknik Simple Random Sampling yaitu metode pemilihan sampel yang setiap anggota populasinya mempunyai peluang yang sama untuk dipilih menjadi anggota sampel (Umar, 2004). Jumlah sampel diambil secara langsung dari populasi dengan menggunakan rumus penarikan sampel oleh Yamane (1967) dalam Rahmat (1999) yaitu 93 Responden.

Kuesner penelitian ini didesain dengan mengajukan sejumlah pertanyaan yang sesuai dengan indikator-indikator yang telah dipilih terlebih dahulu. Setiap pertanyaan memiliki 7 alternatif pilihan jawaban yang dibuat berdasarkan Skala Semantic Differential yang dikembangkan sedemikian rupa agar memudahkan responden dalam menjawab seluruh pertanyaan. Data yang diperoleh dari hasil penelitian kemudian diolah menggunakan teknik analisis data yaitu Partial Least Square (PLS).

Tahapan yang digunakan untuk menganalisis data, yaitu:

a. Confirmatory Factor Analysis (Analisis Faktor Konfirmatori).

b. Analisis Regresi Berganda, dengan persamaan :

$$
\begin{aligned}
& \mathrm{X} 2=\beta 0+\beta 1 \mathrm{X} 1 \\
& \mathrm{X} 3=\beta 0+\beta 1 \mathrm{X} 1+\beta 2 \mathrm{X} 2 \\
& \mathrm{Y}=\beta 0+\beta 3 \mathrm{X} 3 \\
& \mathrm{Z}=\beta 0+\beta 4 \mathrm{Y} 1+\mathrm{e}
\end{aligned}
$$

Path analysis (analisis jalur) 
Validitas dan Reliabilitas Konstruk Kriteria validitas indikator diukur dengan convergent validity pada uji kuesner terhadap 20 responden.

Indikator dikatakan valid dengan standar nilai convergent validity nilai loading diatas 0,6. Validitas dapat dapat pula ditunjukkan oleh nilai Average Variance Extracted (AVE) yang berada diatas nilai 0.50.

Variabel Nilai AVE ASU 0,814975 ATU 0,583403 BIU 0,877055 PEOU 0,680369 PU 0,750613 Reliabilitas variabel diukur dengan nilai Composite Reliability . Variabel dapat dikatakan reliabel jika memiliki nilai Composite Reliability di atas 0,70 .

\section{HASIL DAN PEMBAHASAN}

Resampling Bootstraping dengan software PLS mengungkapkan nilai Rsebagai berikut :

\section{R Square}

PU 0,531 ATU 0,702 BIU 0,549 ASU 0,131 Pengaruh variabel PEOU PU memberikan nilai R-Square 0,531 yang dapat diinterpretasikan bahwa Composite Reliability Resampling Bootstraping dengan software PLS mengungkapkan nilai $\mathrm{R}$ 2 R Square PEOU terhadap Square sebesar 0,531 yang dapat diinterpretasikan bahwa variabilitas konstruk PU dapat dijelaskan oleh variabilitas konstruk 53,1\% sedangkan 46,9\% dijelaskan oleh variabel lain diluar yang diteliti. Demikian halnya variabilitas konstrukdijelaskan oleh variabilitas konstruk dan PU sebesar 70,2\% sedangkan 29,8\% dijelaskan oleh variabel lain, konstruk BIU dapat dijelaskan oleh variabilitas konstruk ATU sedangkan $45,1 \%$ dijelaskan oleh variabel lain serta variablitas konstrukdijelaskan oleh variabilitas konstruksebesar 13,1\% sedangkan $86,9 \%$ dijelaskan ole $\mathrm{h}$ variabel lain. Hasil olahan data nilai hubungan antara variabel secara visual, dan hasil bootstrapping olahan data masingvariabel dapat dilihat bahwa keseluruhan nilai koefisien dari tiap hubungan berada pada tingkatan positif dan nilai t statistik dari tiap hubungan dapat dijelaskan PEOU sebesar 53,1\% sedangkan 46,9\% dijelaskan oleh variabel lain diluar yang diteliti. Demikian halnya variabilitas konstruk ATU dapat dijelaskan oleh variabilitas konstruk PEOU sebesar $70,2 \%$ sedangkan $29,8 \%$ dijelaskan oleh variabel lain, variablitas dapat dijelaskan oleh ATU sebesar 54,9\% sedangkan 45,1\% dijelaskan oleh variabel lain serta variablitas konstruk ASU dapat dijelaskan oleh variabilitas konstruk BIU sebesar $13,1 \%$ sedangkan $86,9 \% \mathrm{~h}$ variabel lain. Hasil olahan data nilai hubungan antara variabel secara visual, dan hasil olahan data masing -masing variabel .Hal ini menunjukkan bahwa keseluruhan nilai koefisien dari tiap hubungan berada pada tingkatan positif dan nilai t statistik dari tiap hubungan variabel lebih besar daripada 
nilai $t$ tabel yaitu 1,99. Namun berdasarkan standar signifikansi koefisien parameter yang diungkapkan oleh Bagozzi (1996) dalam Chiam (2006) bahwa nilai koefisien parameter dianggap signifikan jika lebih besar dari 0,6 sehingga pengaruh variabel PU terhadap variabel ATU dan pengaruh variabel BIU terhadap variabel ASU dianggap tidak signifikan. Masing-masing hipotesis dijabarkan sebagai berikut:

Hipotesis pertama : perceived ease of use mempunyai pengaruh terhadap perceived usefulness. Berdasarkan hasil uji hipotesis pertama, terbukti adanya pengaruh yang positif dan signifikan antara variabel PEOU terhadap PU sebesar 0,729. Kemudahan penggunaan akan mengurangi usaha (baik waktu dan tenaga) seseorang dalam mempelajari suatu sistem informasi. Perbandingan kemudahan tersebut memberikan indikasi bahwa karyawan yang menggunakan suatu sistem informasi lebih mudah menyelesaikan pekerjaannya dibandingkan dengan karyawan yang bekerja tanpa menggunakan sistem (secara manual). Pengguna sistem informasi mempercayai bahwa sistem yang lebih fleksibel, mudah dipahami dan mudah pengoperasiannya (compartible) sebagai karakteristik kemudahan penggunaan, akan memutuskan untuk menggunakan sistem tersebut dalam menyelesaikan pekerjaannya. Temuan studi Iqbaria (1994) membuktikan bahwa teknologi informasi digunakan bukan mutlak karena adanya tekanan sosial, sehingga Iqbaria menyimpulkan bahwa penggunaan teknologi informasi bukan karena adanya unsur tekanan, tetapi karena memang mudah digunakan, sehingga berujung pada kemanfaatan.

Hipotesis kedua : perceived ease of use mempunyai pengaruh terhadap attitude toward using. Pengujian hipotesis kedua membuktikan adanya pengaruh yang positif dan signifikan antara variabel PEOU terhadap ATU sebesar 0,601. Berdasarkan telaah teoritis, bahwa penerimaan penggunaan sistem ERP yang dipersepsikan, juga turut dipengaruhi oleh kemudahan penggunaannya, ini merupakan refleksi psikologis pengguna yang lebih bersikap terbuka terhadap sesuatu yang sesuai dengan apa yang dipahaminya dengan mudah. Persepsi kemudahan tersebut dapat mendorong seseorang untuk menerima menggunakan sistem ERP . Penelusuran kepada sejumlah responden, ditemukan fakta bahwa meskipun sistem J.D.Edwards telah diimplementasikan di PT Semen Gresik kurang lebih 8 tahun, namun masih terdapat berbagai hal atau fitur tertentu yang dirasakan sulit atau menyulitkan user, beberapa hal ini diungkapkan oleh responden, bahwa:

a. Koneksi jaringan ke sistem sering lambat,

b. Belum bisa menampilkan prognose secara akurat,

c. Fitur Display Anggaran Biaya dan Realisasi yang tidak bisa ditampilkan secara bulanan,

d. Fitur RNVOA tidak menunjukkan hasil yang sama dengan saldo neraca,

e. Fitur Bill of Material untuk equipment, tergolong masih general, dan 
f. Modul belum bisa terintegrasi langsung, untuk segera pengambilan keputusan.

Ungkapan responden tersebut merupakan bagian dari faktor-faktor penyebab yang menurunkan persepsi sebagian user bahwa sistem ERP yang diterapkan sudah benar-benar mudah digunakan dan memudahkan penyelesaian pekerjaan. Analisa lebih lanjut dapat mengungkapkan bahwa beberapa kendala yang ditemukan tersebut merupakan sebagian dari faktor-faktor yang memungkinkan menjadi penyebab nilai R-Square ATU dari PU dan PEOU tidak teruji sebesar $31,58 \%$.

Hipotesis ketiga : perceived usefulness mempunyai pengaruh terhadap attitude toward using. Temuan dari dugaan hipotesis ketiga membuktikan adanya pengaruh yang positif namun tidak signifikan antara variabel PU terhadap ATU sebesar 0.291. Hasil pembuktian hipotesis ini juga megindikasikan bahwa secara umum, end-user telah merasakan manfaat dari sistem ERP berupa kemudahan dalam penyelesaian pekerjaan maupun peningkatan produktivitas pekerjaan mereka sehingga timbulnya kesadaran akan pentingnya sistem tersebut diterapkan dengan baik. Namun nilai pengaruh yang ditemukan tidak signifikan artinya pengaruh perceived usefulness tidak terlalu besar untuk meningkatkan attitude toward using, hal ini mendorong penelusuran lebih lanjut pada sejumlah responden di PT Semen Gresik dan menghasilkan informasi bahwa masih terdapat beberapa fitur atau halhal yang berkaitan dengan sistem ERP yang dianggap kurang bermanfaat, antara lain:

a. Fitur-fitur yang tidak sesuai dengan unit kerja.

b. Terlalu banyak pengisian ID sehingga efisiensi waktu berkurang.

c. Beberapa fasilitas jarang di-update sehingga tidak optimal.

d. Terdapat Tool / tampilan menu yang berbeda namun memiliki fungsi yang sama

e. Fitur instruction, record types dan laporan kerja, dan

f. Downtime management .

Sejumlah informasi tersebut dapat menjadi indikasi rendahnya nilai pengaruh dari persepsi manfaat sebuah sistem informasi terhadap sikap penerimaan user, dan juga merupakan tambahan wawasan yang dapat dianggap sebagai bagian dari faktorfaktor yang memungkinkan menjadi penyebab nilaiR-Square ATU dari PU dan PEOU tidak teruji sebesar 31,58\% karena hal-hal tersebut hanya merupakan sebagian kecil dari fitur sistem J.D.Edwards sedangkan fitur yang lainnya tentu dianggap bermanfaat diimplementasikan. 
Hipotesis keempat : attitude toward using mempunyai pengaruh terhadap behaviour intention to use. Berdasarkan hasil uji hipotesis keempat, terbukti adanya pengaruh yang positif dan signifikan antara variabel ATU terhadap BIU sebesar 0,741. Hasil penelitian ini mendukung temuan penelitian Malhotra and Galetta (2009), Gyampah and Salam (2003), dan Nelvia dan Rudi (2009) yang menyatakan bahwa aspek behavior dalam penerapan sistem informasi menjadi aspek yang sangat penting karena interaksi antara pengguna dengan perangkat sistem informasi sangat dipengaruhi oleh persepsi, sikap dan afeksi sebagai aspek keprilakuan yang melekat pada diri manusia sebagai user, sehingga sistem yang dikembangkan oleh suatu perusahaan haruslah berorientasi kepada penggunanya. Informan dari Divisi Sistem Informasi PT Semen Gresik menyatakan bahwa secara umum penggunaan sistem J.D.Edwards sudah tergolong baik dan lancar, karena bisnis proses yang ada di sistem J.D.Edwards telah di adaptasikan dengan bisnis proses yang berlaku di perusahaan, namun terdapat modul yang tidak diimplementasikan yaitu modul Human Resource Management (Manajemen Sumber Daya Manusia). Hal ini bukan berarti sikap penolakan atau resistensi akan tetapi tidak dimanfaatkannya modul HRD karena beragam aturan dan kebijakan perusahaan mengenai karyawan yang tidak sama dengan aturan yang ada di dalam sistem J.D.Edwards, dan lebih kepada alasan standarisasi budaya kerja masyarakat luar negeri tidak mungkin disamakan dengan budaya dan kewenangan terhadap pekerja di Indonesia.

Hipotesis kelima : behavior intention to use mempunyai pengaruh terhadap actual system use. Hasil uji hipotesis kelima membuktikan adanya pengaruh yang positif namun tidak signifikan antara variabel BIU terhadap ASU sebesar 0,362. Aspek behavoir intention to use mencerminkan adanya konsistensi penggunaan sistem ERP di masa yang akan datang. Hal ini ditunjukkan perusahaan PT Semen Gresik yang mempercayai sistem ERP merupakan sistem yang powerfull untuk menunjang segala aspek pekerjaan di setiap divisi, sehingga akan tetap menerapkannya meskipun pengaruh kebijakan para shareholder yang menetapkan bahwa sistem J.D.Edwards akan digantikan dengan produk ERP yang lain yaitu sistem SAP . Terkait dengan rencana penggantian sistem JD.Edwards ke sistem SAP , beberapa hal diungkapkan oleh responden, sebagai berikut:

Harapan responden agar fitur-fitur dalam sistem SAP lebih sederhana (user friendly ), dapat diakses oleh semua karyawan, dan lebih soft sehingga tidak terlalu mempengaruhi perubahan pola kerja karyawan yang sudah berjalan.

a. fitur-fitur dalam sistem SAP lebih optimal, penyempurnaan integrasi antar modul dan dapat mengakomodir kebutuhan user.

b. Pentingnya untuk semua user dapat diikutkan pelatihan sistem SAP secara intensif. 


\section{KESIMPULAN}

Berdasarkan hasil analisis data dan pembuktian hipotesis yang telah diuraikan dalam pembahasan, maka peneltian ini dapat menyimpulkan beberapa hal, antara lain:

Terdapat pengaruh yang signifikan dari perceived ease of use terhadap perceived usefulness dalam penerapan teknologi ERP. Persepsi bahwa semakin mudah suatu teknologi digunakan, semakin tinggi tingkat kemanfaatan teknologi tersebut, selaras dengan pemaparan teoritis yaitu persepsi end-user bahwa sistem informasi yang mereka temui bersifat mudah atau sulit digunakan, didasarkan pada pengalamannya dalam menggunakan sistem informasi, dan selanjutnya akan membentuk persepsi bahwa sistem tersebut bermanfaat atau tidak.

Terdapat pengaruh yang signifikan dari perceived ease of use terhadap attitude toward using dalam penerapan teknologi ERP. Persepsi bahwa semakin mudah suatu teknologi digunakan, semakin tinggi tingkat penerimaan pengguna untuk memanfaatkan teknologi tersebut, sesuai dengan kesimpulan dari Utaminingsih (1998) yang menyatakan bahwa persepsi-persepsi yang ditimbulkan seseorang, akan membentuk sikap menerima atau menolak sistem informasi, karena pada dasarnya manusia hanya menolak sesuatu yang mereka takuti atau tidak dipahami.

Terdapat pengaruh yang tidak signifikan dari perceived usefulness terhadap attitude toward using dalam penerapan teknologi ERP, atau dengan istilah lain variasi nilai perceived usefulness tidak mampu mempengaruhi perubahan attitude toward using. Tingkat kemanfaatan suatu teknologi yang dipersepsikan, berpengaruh rendah terhadap tingkat penerimaan pengguna untuk memanfaatkan teknolgi tersebut.

Terdapat pengaruh yang signifikan dari attitude toward using terhadap behavior intention to use dalam penerapan teknologi ERP. Semakin tinggi tingkat penerimaan pengguna terhadap suatu teknologi, semakin tinggi pula minat pengguna untuk berperilaku menggunakan teknologi tersebut. Kesadaran akan pentingnya penggunaan sistem ERP dalam menunjang pekerjaan karyawan kemudian diwujudkan dengan keinginanan untuk benar-benar mengakses sistem ERP dan tetap mempergunakannya dimasa yang akan datang.

Terdapat pengaruh yang tidak signifikan dari behavior intention to use terhadap actual system use dalam penerapan teknologi ERP, atau dengan istilah lain variasi nilai behavior intention to use tidak mampu mempengaruhi perubahan actual system use. Tingkat minat pengguna untuk berperilaku menggunakan suatu teknologi berpengaruh rendah terhadap tingkat intensitas atau frekuesi penggunaan teknologi 
tersebut. Hubungan pengaruh kedua variabel ini ditegaskan oleh Fishbein dan Ajzen (1975) dalam Theory of Planned Behavior bahwa "minat seseorang adalah untuk melakukan suatu perilaku, karena minat merupakan variabel antara yang terjadinya perilaku dari suatu sikap maupun variabel lainnya".

\section{DAFTAR PUSTAKA}

Amoako-Gyampah, Kwasi and Salam A.F. 2003. An Extension of the Technology Acceptance Model in an ERP Implementation Environment. Information \& Management Journal 41, pp 731-745.

Antoni, Yoyok, 2000. Pengaruh Penggunaan Teknologi Informasi Terhadap Prestasi Kerja Manajer Menengah (Studi Pada Perusahaan Perbankan / Jasa Keuangan dan Consumer Goods yang Terdaftar di BEJ) . Master Tesis. Program Pascasarjana, Universitas Brawijaya. Malang.

Asna. 2001. Pengaruh Sikap Terhadap Minat Berperilaku serta Perilaku Individu (Studi pada Nasabah Tahapan BCA Kantor Cabang Pembantu Sudirman, Malang). Master Tesis. Program Pascasarjana, Universitas Brawijaya. Malang.

Calisir, Fethi et al . 2009. Predicting the Behavioral Intention to Use Enterprise Resource Planning Systems, An Exploratory Extension of the Technology Acceptance Model. Management Research News. Emerald Group Publishing Limited. Vol. 32 No. 7. pp. 597-613.

Carton, Fergal and Frederic Adam. 2005. Understanding the Impact of Enterprise Systems on Management Decision Making: An Agenda for Future Research. Electronic Journal of Information Systems Evaluation Volume 8 Issue 2 pp 99-106.

Chiam, Michael. 2006 . Willingness to Buy from Internet Web Sites - A Sugested Model. Thesis for Doctor of Philosophy at The University of Western Australia.

Cozby, Paul C. 2009. Methods in Behavioral Research . Edisi Ke-9. Pustaka Pelajar. Yogyakarta.

Dajan, A. 1995. Pengantar Metode Statistik . Jilid I. Pustaka LP3ES Indonesia. Jakarta. 
Davis Fred D. 1989. Perceived Usefulness, Perceived Ease of Use, and User Acceptance of Information Technology . MIS Quarterly, pp 318 - 340.

Davis, B. Gordon. 1999. Management Information Systems: Conceptual Foundations, Stucture, and Development . Part Two. McGraw-Hill Kogakusha, Ltd, Tokyo. Bob Widyahartono (penterjemah) 1984. Konsep Dasar Sistem Informasi Manajemen, Struktur dan Pengembangannya. Edisi Kedua. PT Pustaka Binaman Pressindo. Jakarta. Dermawan, Rizky. 2006. Pengambilan Keputusan . Alfabeta. Bandung.

Dhewanto, Wawan dan Falahah. 2007. ERP (Enterprise Resource Planning) Menyelaraskan Teknologi Informasi dengan Strategi Bisnis . Informatika Bandung. Bandung.

Dina. 2008. DSS (Decision Support System) . http://dina06121084.blogspot.com/2008_10_01_archive.html. Diakses: 22 Desember 2009

Ellitan, Lena dan Lina Anatan. 2007. Sistem Informasi Manajemen: Konsep dan Praktis . Alfabeta. Bandung

Etezady, Nooredin. 2008. The Impact of ERP Investments on Organizational Performance . Doctoral Dissertation. Graduate School of Computer and Information Sciences Nova Southeastern University.

Fishbein, Martin and Ajzen, Izek. 1975. Belief Attitude, Intention and Behavior : An Introduction to Theory and Research Addison. Wesley Publishing Co. Massachusetts.

Ghozali, Imam. 2001. Aplikasi Analisis Multivariate dengan Program SPSS . Edisi 1. Badan Penerbit Universitas Diponegoro. Semarang. 2005. Aplikasi Analisis Multivariate Dengan Program SPSS . Universitas Diponegoro. Semarang.

2008. Structural Equation Modeling, Metode Alternatif dengan Partial Least Square . Edisi 2. Badan Penerbit Universtas Diponegoro. Semarang.

Hatzithomas, Leonidas, et al . 2007. Quality And Effectiveness Of Enterprise Resource Planning - Customer Relationship Management Systems: Implications For Information Systems Marketing Strategic. The Journal of Applied Business Research - Third Quarter 2007 Volume 23, Number 3. 
Humaedi, Dedi. 2003. Ketika Sang Juragan Semen Ingin Naik Kelas . http://www.swa.co.id/swamajalah/swadigital/detail s.php?cid=1\&id=1973\&pageNum=1. Diakses: 21 Januari 2010.

Husein, Muhammad Fakhri dan Wibowo. 2002. Sistem Informasi Manajemen . Edisi Revisi. Unit Penerbit dan Percetakan AMP YKPN. Yogyakarta.

Ifinedo, Princely and Nazmun Nahar. 2006. Quality, Impact and Success of ERP Systems: A Study Involving Some Firms in the Nordic-Baltic Region. Journal of Information Technology Impact Vol. 6, No. 1, pp 19- 46. Iqbaria M,.1994. An Examination Of The Factors Contributing To Micro Computer Techenology Acceptance . Journal of Information system, Elsiever Science, USA.

Jabri and Hadab. 2008. End User Adoption of ERP Systems : Investigation of four Beliefs . Journal from King Fahd University of Petroleum \& Minerals, College of Industrial Management. Department of Accounting and MIS. Saudi Arabia.

Jahangir, Nadim and Noorjahan Begum. 2007. The Role Of Perceived Usefulness, Perceived Ease Of Use, Security And Privacy, And Customer Attitude To Engender Customer Adaptation In The Context Of Electronic Banking . African Journal of Business Management Vol.2 (1), pp. 032-040.

Jogiyanto, HM. 2007. Sistem Informasi Keperilakuan . Penerbit Andi. Yogyakarta. Yogyakarta.

Kamhawi, Emad M. 2008. System Characteristics, Perceived Benefits, Individual Differences and Use Intentions : a Survey of Decision Support Tools of ERP Systems . Information Resource Management Journal, 21(4), pp 66-83.

Kerlinger, Fred N. 1990. Foundations of Behavioral Research . Third Edition by Holt, Rinehart and Winston Inc. Landung R. Simatupang (penterjemah). 1986. Asas-Asas Penelitian Behavioral. Edisi Ketiga. Gajah Mada University Press. Yogyakarta. Kioskea. 2008. Introduction to the Groupware Concept . http://en.kioskea.net/contents/entreprise/groupware. php3. Diakses: 22 Desember 2009 Kositanurit, Boontaree, et al . 2006. An exploration of factors that impact individual performance in an ERP environment: an analysis using multiple analytical techniques. European Journal of Information Systems 15, pp 556-568. 
Laudon, Kenneth C and Jane P.Laudon. 2004. Management Information Systems, Managing the Digital Firm, Eight Edition . Pearson Education, Inc. Erwin Phillipus (penterjemah) 2005. Sistem Informasi Manajemen, Mengelola Perusahaan Digital. Edisi Delapan. Penerbit Andi. Yogyakarta.

Lee, Younghwa, et al . 2003. The Technology Acceptance Model: Past, Present, And Future . Communications of the Association for Information Systems (Volume 12, Article 50) pp 752-780. Malhotra, Yogesh and Dennis F. Galletta. 1999. Extending the Technology Acceptance Model to Account for Social Influence: Theoretical Bases and Empirical Validation . Proceedings of the 32 nd Hawaii International Conference on System Sciences.

Masbow. 2009. Apa itu Persepsi? . All About Psychology. http://www.masbow.com/2009/08/apa-itu- persepsi.html. Diakses: 12 November 2009

McLeod, Raymond Jr. and George P. Schell. 2007. Management Information System. Ninth Edition. Pearson Prentice Hall, Inc. Heri Yulianto (penterjemah) 2007. Sistem Informasi Manajemen. Edisi Kesembilan. PT Indeks.

Jakarta

Mohammad, A. BS. 2008. PT. Bumi Serpong Damai (BSD) City Pakai ERP SAP. http://www.swa.co.id/primer/swadigital/manajementi /details.php?cid=1\&id=7855. Diakses: 19 Desember 2009.

Nah, Fiona Fui-Hoon, Xin Tan, et al . 2004. An Empirical Investigation on EndUsers' Acceptance of Enterprise Systems . Information Resources Management Journal, 17(3), pp 32-53.

Nasution, Fahmi Natigor. 2004. Penggunaan Teknologi Informasi Berdasarkan Aspek Perilaku (Behavioral Aspect). Digitized by USU digital library. Fakultas Ekonomi Universitas Sumatera Utara.

Nazir, Moh. 2003. Metode Penelitian . Ghalia Indonesia. Jakarta.

Nelvia, Desi dan Rudy M. Harahap. 2009. Studi atas Prilaku Pengguna Layanan Wide Area Network (WAN) BPKP . Internetworking Indonesia Journal. Vo.1/No.1, hal. 25-28.

Nur Indriantoro. 2000. Pengaruh Computer Anxiety Terhadap Keahlian Dosen dalam Penggunaan Komputer. Jurnal Akuntansi dan Auditing (JAAI), 
Volume 4 no 2 Desember, Fakultas Ekonomi, Universitas Islam Indonesia (UII), Yogyakarta.

Nurhasanah, Andi. 2004. Sikap dan Perilaku serta Pengaruhnya Terhadap Penerapan Sistem. Master Tesis. Program Pascasarjana, Universitas Brawijaya. Malang.

O’Brien, James A. 1993. Management Information Systems: a Managerial EndUser Perspective . Richard D. Irwin, Inc. Boston.

Olson, David L. 2004. Managerial Issues of Enterprise Resource Planning Systems. International Edition. McGraw-Hill. New York.

Park, Sung et al . 2006. Acceptance Of Computer Technology: Understanding The User And The Organizational Characteristics. PROCEEDINGS Of The HUMAN FACTORS AND ERGONOMICS SOCIETY 50th ANNUAL MEETING. Georgia Institute Of Technology.

Pravita, Sylviana. 2010. Efisiensi Angkat Laba Semen Gresik . http://web.bisnis.com/edisi-cetak/edisi- harian/bursa/1id156262.html. Diakses: 20 Januari 2010.

Psychemate. 2009. Self Efficacy . http://psychemate.blogspot.com/2007/12/selfefficacy.html. Diakses : 28 Mei 2010

Rahmat, Jalaluddin. 1999. Penelitian Komunikasi . Remaja Rosdakarya. Jakarta.

Ramayah T and May-Chiun Lo. 2007. Impact Of Shared Beliefs On "Perceived Usefulness" And "Ease Of Use" In The Implementation Of An Enterprise Resource Planning System . Management Research News Vol. 30 No. 6 pp. 420-431.

Robbins, Stephen P. 2002. Prinsip-prinsip Perilaku Organisasi . Edisi Kelima. Erlangga. Jakarta.

Santoso,S. 2003. Statistik Multivariat . Penerbit PT Elex Media Komputindo. Jakarta.

Setiabudi. 2008. Tinjauan Beberapa Pemimpin Produk ERP (Enterprise Resources Planning) . http://www.setiabudi.name/archives/365. Diakses: 22 Januari 2010.

Seyrek, Ybrahim Halil and Mehmet Aytekyn. 2008. Features Of Enterprise Resource Planning Systems That Can Help Decision Making: The Users 
Perspective. Journal of Global Strategic Management. Gaziantep University, Turkey Siagian, Sondang P. 1990. Sistem Informasi untuk Pengambilan Keputusan . CV Haji Masagung. Jakarta.

Sidharta, Lani. 1995. Pengantar Sistem Informasi Bisnis . PT Alex Media Komputindo. Jakarta.

Singarimbun dan Effendi. 2006. Metode Penelitian Survey. Pustaka LP3ES. Jakarta.

Subakti, Irfan. 2002. Sistem Pendukung Keputusan (Decision Support System) . Fakultas Teknologi Informasi. Institut Teknologi Sepuluh Nopember, Surabaya. Sugiyono. 2001. Metode Peneltian Administrasi. Penerbit Alfabeta. Bandung.

Sulaiman,W. 2004. Analisis Regresi Menggunakan SPSS . Penerbit Andi. Yogyakarta

Syamsi, Ibnu. 2000. Pengambilan Keputusan dan Sistem Informasi . Bumi Aksara. Jakarta.

Syam Fazli BZ.1999. Dampak Kompleksitas Teknologi Informasi Bagi Strategi dan Kelangsungan Usaha, Jurnal Akuntansi dan Auditing (JAAI) Vol.3 no.1, FE. UII Yogyakarta

Syarip, Dodi Irawan dan Dana Indra Sensue. 2007. Kajian Penerimaan Teknologi Internet pada Organisasi Pemerintah Berdasarkan Konsep Technology Acceptance Model (TAM) : Studi Kasus Direktorat Jenderal Pendidikan Islam Departemen Agama R.I. Jurnal Sistem Informasi MTI UI Vol.3 No.1 hal.1-11

Tampubolon, Manahan P. 2004. Perilaku Keorganisasian . Ghalia Indonesia. Jakarta.

Tarigan, Zeplin Jiwa Husada. 2009. Pengaruh Key User, Terhadap Kinerja Perusahaan Pada Implementasi Teknologi Enterprise Resources Planning. Proposal Disertasi. Universitas Kristen Petra, Surabaya.

Taylor, Shirley and Peter A.Todd. 1995. Understanding Information Technology Usage: A Test of Competing Models . Institute for Operation Research and 
the Management Sciences. Information Systems Research Journal 6:2 pp.144-176

Trisnawati Rina.1998. Pertimbangan Prilaku Dan Faktor Penentu Keberhasilan Pengembang Sistem Informasi . Jurnal kajian bisnis, edisi September, Yogyakarta

Umar, Husein. 2004. Metode Riset Ilmu Administrasi, Ilmu Administrasi Negara, Pembangunan, dan Niaga . PT Gramedia Pustaka Utama. Jakarta.

Utaminingsih, Alifiulahtin. 1998. Faktor-faktor yang mempengaruhi keterlibatan pengguna untuk mendukung implementasi sistem informasi berbasis komputer. Master Tesis . Program Pascasarjana, Universitas Brawijaya.

Uziek . 2009. Enterprise Resource Planning (ERP). http://uziek.blogspot.com/ 2009/07/erp.html. Diakses: 22 Desember 2009

Wang, Wen Hung and Yi Jyun Liu. 2009. Attitude, Behavioral Intention and Usage: An Empirical Study of Taiwan Railway's Internet Ticketing System . http://www.swdsi.org/swdsi2009/Papers/9C04.pdf . Diakses: 1 November 2009.

Whitten, Jeffery L, Lonnie D.Bentley, et al. 2004. Systems Analysis and Design Methods . Original English edition copyright 2004 by The McGraw-Hill Companies, Inc. Tim Penerjemah ANDI. Metode Desain dan Analisis Sistem. Edisi Enam. Penerbit Andi. Yogyakarta.

Wibowo, Arief. 2008. Kajian Tentang Perilaku Pengguna Sistem Informasi dengan Pendekatan Technology Acceptance Model (TAM). Makalah - Makalah Sistem Informasi. Prosiding Konferensi Nasional Sistem Informasi (KNSI) 2008. Informatika. Bandung

Widhiarso, 2004. Evaluasi Faktor Dalam Big Five : Pendekatan Analisis Faktor Konfrmatori. Program Pascasarjana Universitas Gadjah Mada. Yogyakarta. http://widhiarso.staff.ugm.ac.id/files/analisis_fakto r_konfirmatori_big_five.pdf. Diakses : 6 Desember 2009.

Wijaya, Santo F dan Suparto Darudiato. 2009. ERP (Enterprise Resource Planning) dan Solusi Bisnis . Graha Ilmu. Yogyakarta.

Wijaya. 2001. Analisis Statistik dengan SPSS 14.00, Penerbit Alfabeta, Bandung.

Winardi. 2004. Manajemen Perilaku Organisasi . Kencana Prenada Media Group. Jakarta. 
Wirawan, Judithia A. 2010. Motivasi Kerja, dalam konteks Psikologi Organisasi.

http://rumahbelajarpsikologi.com/index2.php?opti on=com_content\&do_pdf=1\&id=43. Diakses: 28 Mei 2010.

Wiyono, Adrianto Sugiarto, dkk. 2009. Aspek Psikologis pada Implementasi Sistem Teknologi Informasi. http://rianadrianto.files.wordpress.com/2008/06/ps ikologi-proyek-si.pdf. Diakses:16 September 2009.

Yingjie, Jiang. 2005. Critical Success Factors in ERP Implementation in Finland . Master Thesis. The Swedish School of Economics and Business Administration.

Yusoff, Yusliza Mohd, et al . 2009. Individual Differences, Perceived Ease Of Use, And Perceived Usefulness In The E-Library Usage. Computer and Information Science. Vol.2 No.1.

Zuhri, Amiruddin. 2002. Pengaruh Kemampuan Pemakai Akhir dan Penerimaan Sistem Informasi yang Berbasis Komputer terhadap Kepuasan Pemakai Akhir. Master Tesis. Program Pascasarjana, Universitas Brawijaya. Malang.

http://insidewinme.blogspot.com/2008/02/perusahaanmenggunakan-erpsystem.html. Diakses: 02 Agustus 2009.

http://proquest.umi.com/pqdweb/?cfc=1. Diakses : 02 September 2009

http://www.erpweaver.com/index.php. Diakses: 19 Desember 2009

http://www.semengresik.com. Diakses: 10 Januari 2010.

http://www.smartpls.de. Diakses: 01 November 2009. 